ARTICLE HISTORY: Received: September 13, 2021 Accepted: November 5, 2021 Published: November 13, 2021

ЗАРУБЕЖНЫЕ МОДЕЛИ ГОСУДАРСТВЕННОГО РЕГУЛИРОВАНИЯ ПОТРЕБИТЕЛЬСКОГО ПОВЕДЕНИЯ: СРАВНИТЕЛЬНЫЙ АНАЛИЗ

Махмудова Гулрух Равщанбековна

аспирант

Казанский федеральный университет,

Казань, Россия

\title{
FOREIGN MODELS OF STATE REGULATION OF CONSUMER BEHAVIOR: RESEARCH BY COMPARISON
}

\author{
Makhmudova Gulrukh Ravshanbekovna \\ graduate student \\ Kazan Federal University, \\ Kazan, Russia
}

\begin{abstract}
Аннотация. В работе выделены основные элементы зарубежных моделей развития потребительского поведения, которые могут быть использованы в практике совершенствования оказывающих влияние на его содержание институтов и механизмов в современной национальной экономике РФ. Рассмотрены возможности трансформации в сложившихся в настоящее время условиях хозяйствования отдельных элементов советской модели развития потребительского поведения.

Annotation. The paper highlights the main elements of foreign models of consumer behavior development, which can be used in the practice of improving the institutions and mechanisms that influence its content in the modern national economy of the Russian Federation. The possibilities of transformation in the current economic conditions of individual elements of the Soviet model of the development of consumer behavior are considered.

Ключевые слова: потребительское поведение, предельная полезность, маржинализм, маркетинг, ассиметричность информации, цифровизация.

Key words: consumer behavior, marginal utility, marginalism, marketing, information asymmetry, digitalization.

Исследование особенностей и проблем развития устойчивых зарубежных моделей потребительского поведения экономических субъектов имеет не только теоретико-познавательное, но и прикладное значение. Так, отдельные, наиболее эффективные элементы такого рода моделей, по нашему мнению, могут использованы в целях рационализации систем регулирования потребительского поведения в рамках социально-экономической системы современной России.

Нами систематизированы основные зарубежные модели потребительского поведения, сложившиеся в практике хозяйствования с конца 1990 гг. по 2020-2021 гг. (таблица 1).
\end{abstract}


Основные современные зарубежные модели потребительского поведения (систематизировано автором)

\begin{tabular}{|c|c|c|}
\hline $\begin{array}{c}\text { Наименование } \\
\text { модели }\end{array}$ & $\begin{array}{c}\text { Особенности модели в части } \\
\text { потребительского поведения индивидов и } \\
\text { домохозяйств }\end{array}$ & $\begin{array}{c}\text { Особенности модели в части } \\
\text { потребительского поведения компаний }\end{array}$ \\
\hline 1. Американская & $\begin{array}{l}\text { Дифференциация норм и институтов } \\
\text { регулирования потребительского рынка в } \\
\text { различных штатах. Крайне интенсивная } \\
\text { цифровизация технологий потребления. }\end{array}$ & $\begin{array}{l}\text { Существенная } \\
\text { потребительского поведения корпораций } \\
\text { США от норм института корпоративного } \\
\text { управления, постоянных и достаточно } \\
\text { турбулентных процессов слияний и } \\
\text { поглощений. }\end{array}$ \\
\hline 2. Германская & $\begin{array}{l}\text { Тесная интеграция потребительского } \\
\text { поведения с поведением в области получения } \\
\text { доходов домохозяйствами от долевого участия } \\
\text { в местных компаниях. Широкое развитие } \\
\text { маркетинговых технологий, влияющих на } \\
\text { потребительское поведение. }\end{array}$ & $\begin{array}{l}\text { Полностью либеральная } \\
\text { потребительского поведения компаний, с } \\
\text { минимальным вмешательством государства } \\
\text { в части общего институционального и } \\
\begin{array}{l}\text { антикартельного } \\
\text { регулирования. }\end{array} \\
\end{array}$ \\
\hline 3. Японская & $\begin{array}{l}\text { Сохранение традиций } \quad \text { и обычаев } \\
\text { потребительского поведения, в } \\
\text { сформированных в докапиталистическую } \\
\text { эпоху, минимальные процессы избыточного, } \\
\text { нерационального потребления. }\end{array}$ & $\begin{array}{l}\text { Широкое использование инструментария и } \\
\text { механизмов государственно-частного } \\
\text { партнерства в процессе осуществления } \\
\text { потребительского поведения частных } \\
\text { компаний, в т.ч. крупных корпораций } \\
\text { Японии. }\end{array}$ \\
\hline $\begin{array}{l}4 . \quad \text { Южно- } \\
\text { корейская }\end{array}$ & $\begin{array}{l}\text { Активное стимулирование протекционизма в } \\
\text { рамках } \\
\text { потребительского поведения товаров, работ, } \\
\text { услуг. }\end{array}$ & $\begin{array}{l}\text { Интенсивное использование } \\
\text { территориальных } \\
\text { пластеров в } \quad \text { т.ч. для } \\
\text { повышения } \\
\text { потребительского эффективности } \\
\text { различного масштаба и профиля. }\end{array}$ \\
\hline 5. Бразильская & $\begin{array}{l}\text { Отсутствие выраженного системного подх } \\
\text { потребительского поведения различных груп } \\
\text { влияние коррупционного фактора на потребите } \\
\text { секторе экономики. }\end{array}$ & $\begin{array}{l}\text { ода к регулированию и обеспечению } \\
\text { экономических субъектов. Существенное } \\
\text { ьское поведение, особенно в корпоративном }\end{array}$ \\
\hline 6. Китайская & 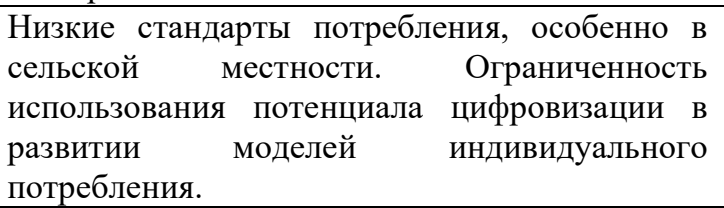 & $\begin{array}{l}\text { Необходимость } \\
\text { стратегических параметров корпоративных } \\
\text { закупок с генеральными пятилетними и } \\
\text { иными планами Правительства КНР. }\end{array}$ \\
\hline $\begin{array}{l}7 . \quad \text { Северо- } \\
\text { корейская }\end{array}$ & $\begin{array}{l}\text { Низкая степень свободы выбора вариантов } \\
\text { потребительского поведения ввиду отсутствия } \\
\text { свободного рынка товаров и услуг. }\end{array}$ & \begin{tabular}{lr} 
Отсутствие & \multicolumn{2}{r}{ самостоятельности } \\
потребительского & поведения \\
действия & ввиду \\
централизованного системы & жестко \\
управления экономикой. & директивного
\end{tabular} \\
\hline
\end{tabular}

Как показано в таблице 1, американская и германская модели потребительского поведения как индивидов, так и корпоративных структур в современных условиях хозяйствования носят выраженно либеральный характер. Для американской модели характерна выраженная цифровизация потребительского поведения как домохозяйств, так и компаний, которая наиболее активно проявилась в 2010 гг. Так, в 2019 г. доля потребления цифровых услуг и товаров через удаленные системы доставки в США составила 31,3\% от суммарного объема потребления домашних хозяйств; в 2020 г., ввиду влияния ситуации пандемийного кризиса, данный показатель возрос до $39,7 \%{ }^{1}$.Для сравнения в экономике РФ в 2020 г. аналогичный показатель составил лишь $12,9 \%{ }^{2}$.

По нашему мнению, интенсивная цифровизация американской модели потребительского поведения граждан США в значительной степени связана с тем, что практически все категории американских граждан, в т.ч. пенсионеры, активно используют потенциал сети Интернет и мобильные приложения в гаджетах для

${ }^{1}$ WorldAnnualReport. NY.,2021. P.231.

${ }^{2}$ Российская экономика: проблемы и перспективы. - М.: Изд-во Института экономической политики, 2021. C.413. 
приобретения товаров и услуг через маркетплейсы и иные электронные системы торговли. В экономике же современной России большинство лиц пенсионного возраста не только не имеют гаджетов с режимами прямого доступа в сеть Интернет, но и вовсе не умеют использовать потенциал последней в целях личного потребления.

Как отмечают, в частности, А. Гриспен и А. Вулджридж характерной особенностью развития потребительского рынка в США является достаточно существенная дифференциация законодательства о товарных рынках и обращении потребительских товаров различного профиля в разных штатах ${ }^{3}$. В особенности такого рода различия касаются оборота таких товаров, как лекарственные средства, токсические препараты, алкогольная продукция, а также банковских, страховых, нотариальных и иных услуг для граждан и организаций. С одной стороны, подобная ситуация дезорганизует потребительское поведение лиц, которые в силу трудовой деятельности или иных факторов вынуждены постоянно менять место жительства. С другой стороны, подобная ситуация сложилась исторически, и полная унификация законодательных систем различных штатов США относительно развития потребительских рынков в настоящее время представляется невозможной.

В экономической системе современной Германии тенденции развития моделей потребительского поведения индивидов и домашних хозяйств тесным образом зависят от особенностей и эффективности функционирования региональных компаний, в первую очередь промышленного профиля. Так, значительная часть населения современной ФРГ не только занята в такого рода корпоративных структурах регионального уровня, но и являются их миноритарными акционерами, причем дивиденды составляют значительную (в среднем 25-30\%) суммарного денежного дохода среднестатистического немецкого домохозяйства. Соответственно, обеспечение как эффективного в производственном и финансовом плане развития региональных промышленных компаний, так и сохранение рациональной модели их дивидендной политики, является даже в сложных социально-экономических условиях пандемийного кризиса 2020-2021 гг. одним из наиболее значимых факторов сохранения интенсивности потребления товаров и услуг домохозяйствами ФРГ на приемлемом уровне.

На модели потребительского поведения граждан Японии, как отмечает, в частности, А.В. Белов в большей степени, чем в других государствах, в первую очередь в США и странах ЕС, оказывают влияние национальные традиции и обычаи 4 . При этом одной из наиболее устойчивых традиций такого рода является отказ от безудержного, иррационального, явно избыточного потребления материальных благ. Напротив, для потребительского поведения большинства жителей современной Японии, в отличие, к сожалению от текущей ситуации в РФ, является ориентация на разноплановое потребление благ духовно-культурного плана. Последнее, в свою очередь, не требует, в отличие от максимизации потребления материальных активов, существенных затрат финансовых ресурсов граждан, и такого рода ресурсы, соответственно, достаточно интенсивно трансформтируются сначала в сбережения, а впоследствии в инвестиции, необходимые для обеспечения расширенного воспроизводства экономических процессов в хозяйстве Японии.

Модель потребительского поведения граждан Южной Кореи, в принципе, формируется по западному, достаточно либеральному образцу. Вместе с тем, для модели потребительского поведения юридических лиц в экономике данного государства характерна интенсивная и разноплановая интеграция в структуру территориальных промышленных кластеров. Кластеры дают возможности осуществлять закупки материалов, комплектующих, производственного оборудования на более привлекательных для компаний финансовоэкономических условиях, обеспечивать более высокий уровень стабильности закупок и снижать тем самым как накладные расходы и трансакционные издержки, связанные с корпоративным потребительским поведением, так и возможные риски, корреспондирующие с процессом закупок.

Модель потребительского поведения, характерная для современной экономической системы КНР, носит смешанный планово-рыночный характер. С одной стороны, экономическое поведение индивидов данного государства является в целом либеральным за исключением возможности доступа граждан Китая ко всему спектру ресурсов сети Интернет, ограниченному законодательно, что затрудняет и покупки ряда цифровых услуг, произведенных за пределами КНР. Потребительская же активность большинства компаний КНР, особенно в тех, в капитале которых есть государственная доля, должна быть согласована с планами и программами Правительства Китая. В этом смысле степень свободы частных китайских корпораций в плане организации и реализации систем потребительского поведения в рамках данной национальной модели является менее существенной по сравнению с рассмотренными ранее моделями потребительского поведения организаций, типичными для США, ФРГ или Японии.

Наконец, модель потребительского поведения, типичная для современной КНДР, носит выраженно военномобилизационный, командно-директивный характер. Уровень жизни граждан данного государства является крайне низким, а покупательные потребности реализуются только в рамках сети государственных магазинов с крайне низким ассортиментом продукции и элементами карточной системы распределения. Интернет-покупки для граждан КНДР недоступны, а черный рынок потребительских товаров, который в СССР 1980 гг. в

${ }^{3}$ Гринспен А., Вулдридж А. Капитализм в Америке. М.: Альпина паблишер, 2020. С.71.

${ }^{4}$ Белов А.В. Япония. Экономика и бизнес. Спб.: Из-во СПбГУ, 2017. С.32. 
определенной степени восполнял проблему дефицита, практически не функционирует. Какая-либо свобода предприятий КНДР в части организации потребительского поведения также отсутствует, а экспортные поставки оборудования и материалов осуществляются в крайне ограниченных объемах и строго контролируются органами национального правительства.

Фактически? именно данная модель является наименее социально эффективной, хотя и относительно устойчивой ввиду жесткого государственного регулирования развития процессов потребления товаров и услуг.

Данные об отношении объемов покупок индивидуальных потребителей по рассматриваемой группе государств в сравнению с современной социально-экономической системой Российской Федерации приведены в таблице 2 .

Таблица 2

Отношение покупок индивидуальных потребителей к ВВП и ставки по потребительским кредитам в государствах, модели потребительского поведения в рамках которых выделены автором, и РФ, 2020 г. $^{5}$

\begin{tabular}{|c|c|c|}
\hline Государства & $\begin{array}{c}\text { Отношение покупок товаров, работ, услуг индивидуальных } \\
\text { потребителей (домохозяйств) к ВВП, \% }\end{array}$ & $\begin{array}{c}\text { Средняя ставка по потребительским } \\
\text { кредитам, \% годовых }\end{array}$ \\
\hline 1. РФ & 46,1 & 44,8 \\
\hline 2. США & 62,4 & 4,9 \\
\hline 3. ФРГ & 63,8 & 3,3 \\
\hline 4. Япония & 55,7 & 6,1 \\
\hline $\begin{array}{c}\text { 5. Южная } \\
\text { Корея }\end{array}$ & 51,9 & 17,4 \\
\hline 6. Бразилия & 44,9 & 6,9 \\
\hline 7. КНР & 40,6 & -6 \\
\hline 8. КНДР & 31,1 & \\
\hline
\end{tabular}

Как показано в таблице 2, доля потребительских покупок индивидуальных покупателей в ВВП России существенно ниже аналогичных показателей, характерных для ведущих государств мира с рыночной экономикой, таких как США, ФРГ, в несколько меньшей степени - Япония.

По нашему мнению, данная ситуация, в первую очередь, обусловлена сравнительно более низким средним уровнем доходов населения России по сравнению с доходами граждан указанных государств, что непосредственно отражается на параметрах покупательной способности.

Вместе с тем, интенсивность покупательной способности населения РФ несколько выше аналогичного показателя по современным экономическим системам Бразилии и КНР - ведущих партнеров России по экономическому союзу БРИКС, а также существенно (на 15,0 процентных пункта в 2020 г.) выше значения данного показателя по экономике КНДР.

С позиций неоклассической экономической теории на интенсивность потребительского поведения домохозяйств существенное влияние оказывает уровень процентных ставок в сегменте банковского потребительского кредитования. Проверим данный тезис на материалах группы государств, приведенных в таблице 2 (кроме КНДР), статистически (рис. 1).

${ }^{5}$ Россия и страны мира: статистический ежегодник. - М.: Изд-во Федеральные службы государственной статистики, 2021. С.25, 251.

${ }^{6}$ В КНДР отсутствует институт потребительского банковского кредитования как таковой 


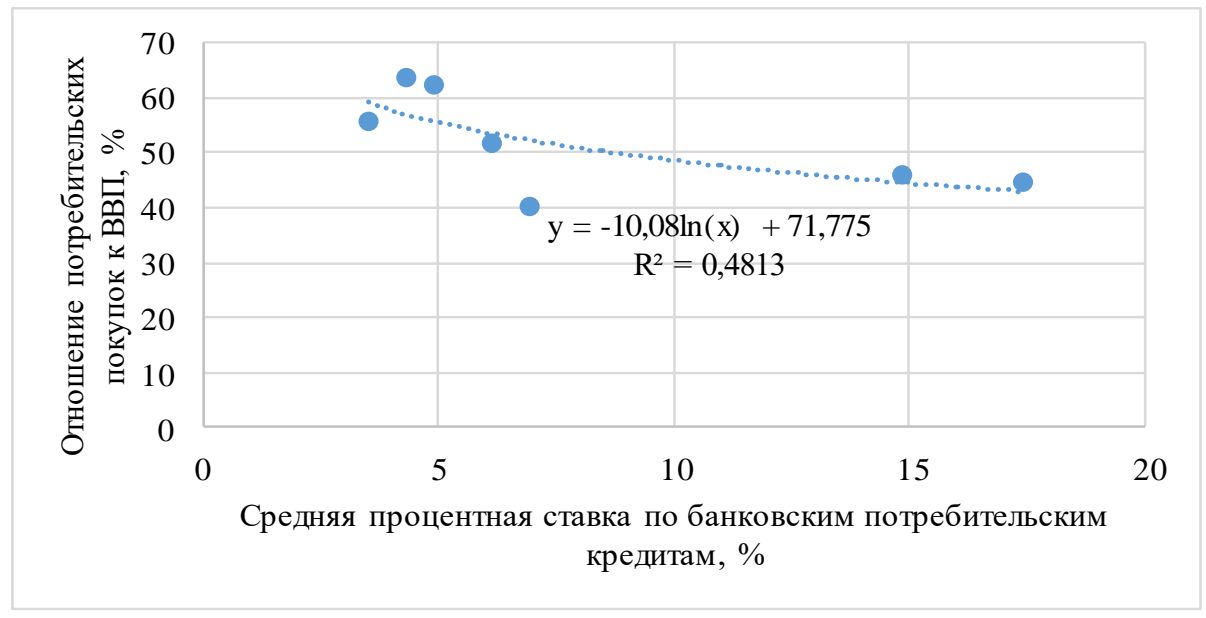

Рис. 1. Экономико-статистическая функция влияния средних ставок по потребительским кредитам на долю потребительских покупок в ВВП по исследуемой группе государств, 2020 г. (построено автором)

Как следует из построенной нами экономико-статистической функции, процентные ставки по потребительским кредитам для физических лиц действительно оказывают обратное влияние на интенсивность покупок домохозяйств государства относительно ВВП. Вместе с тем, подобная зависимость характеризуется средним уровнем статистической устойчивости (по критерию коэффициента парной детерминации $\mathrm{R}^{2}$ ), a также, аппроксимируясь функцией логарифмического вида, носит неэластичный характер. Последнее также является вполне логичным, поскольку на интенсивность потребительского поведения граждан в целом оказывают существенное влияние и иные факторы, такие как, в первую очередь, динамика реальных денежных доходов населения государства, уровень конкурентности развития потребительского рынка, характер и эффективность функционирования института защиты прав и законнных интересов потребителей товаров, работ, услуг.

1. WorldAnnualReport. NY.,2021. P.231

\section{Список литературы}

2. Российская экономика: проблемы и перспективы. - М.: Изд-во Института экономической политики, 2021. С.413.

3. $\quad$ Гринспен А., Вулдридж А. Капитализм в Америке. М.: Альпина паблишер, 2020. С.71.

4. Белов А.В. Япония. Экономика и бизнес. Спб.: Из-во СПбГУ, 2017. С.32.

5. Россия и страны мира: статистический ежегодник. - М.: Изд-во Федеральные службы государственной статистики, 2021. С.25, 251.

6. Автономов, В. Образ человека в политической экономии /В. Автономов // М3 и МО. - 1990. №1. - C.21.

7. Портер, М. Международная конкуренция / М.Портер. - М.: Международные отношения, 1993. $-896 \mathrm{c}$.

8. Сафиуллин Л.Н. Общественное благосостояние в условиях неоднородности рынков. - Казань: Изд-во Казанск. ун-та, 2006. - 269 с.

9. Я Ягаров, Р.С. Истории экономических учении / Р.С.Ядгаров // Учеб. 3-е изд.- М.: ИНФРА-М, 2000. - C.176.

1. WorldAnnualReport. NY.,2021. P.231

2. Russian economy: problems and prospects. - M .: Publishing house of the Institute for Economic Policy, 2021. P.413.

3. Greenspan A., Wooldridge A. Capitalism in America. M .: Alpina publisher, 2020.P.71.

4. A.V. Belov Japan. Economy and business. SPb.: Publishing house of SPbSU, 2017. C.32.

5. Russia and the countries of the world: statistical yearbook. - M .: Publishing house of the Federal State Statistics Service, 2021.C.25, 251.

6. Avtonomov, V. The image of man in political economy / V. Avtonomov // M3 and MO. - 1990. - No. 1. - p.21.

7. Porter, M. International competition / M. Porter. - M .: International relations, 1993. - 896p.

8. Safiullin L.N. Social welfare in a heterogeneous market. - Kazan: Publishing house of the Kazan Federal University, 2006. - 269 pp. 
Yadgarov, R.S. History of economic doctrines / R.S. Yadgarov // Educational 3rd publishing house - M .: INFRA-M, 2000. - P.176. 